\title{
SISTEM BANTU KELAYAKAN KAPAL PELAYARAN PADA PT ASDP KAB. KOLAKA
}

\author{
Qammaddin ${ }^{1)}$ \\ ${ }^{1)}$ Program Studi Sistem Informasi \\ Fakultas Teknologi Informasi Universitas Sembilanbelas November Kolaka \\ e-mail: didinusn@,gmail.com ${ }^{1)}$
}

\begin{abstract}
ABSTRAK
Penelitian ini bertujuan untuk menganalisis faktor-faktor yang kelayakan kapal dalam melakukan pelayaran untuk menghindari terjadinya kecelakaan laut yang berakibat fatal karena tidak layaknya kapal dalam pelayaran dan menyelesaikannya dengan menggunakan pendekatan sistem bantu pengambilan keputusan. Sistem bantu ini berfungsi untuk merekam hasil uji layak laut kapal secara fisik dan administratif sebelum melakukan pelayaran. Sistem bantu dalam penelitian ini dibangun dalam kerangka optimisasi yang dirancang dapat menyelesaikan masalah kelayakan kapal dalam melakukan pelayaran. Uji kelayakan kapal dalam melakukan pelayaran yang baik dan optimal agar terhindar dari kecelakaan yang berakibat fatal tidak mungkin dilakukan tanpa menggunakan sistem pengelolaan data yang baik dan realtime. Dengan sistem bantu, pengolahan data dan parameter kelayakan menjadi lebih cepat dan menghasilkan keputusan yang tingkat keakuratannya tinggi. Melalui penelitian ini, kita mampu meningkatkan kualitas kelayakan kapal dalam pelayaran dengan baik dalam aspek strategis maupun operasional. Penelitian dilakukan dengan menggunakan metode survey, pengembangan model dan sistem bantu pengambilan keputusan. Hasil yang diharapkan adalah berupa prototype dan sebuah sistem bantu uji kelayakan kapal dalam melakukan pelayaran yang dapat diimplementasikan untuk mengatasi dan mengurangi angka kecelakaan laut dalam pelayaran.
\end{abstract}

Kata Kunci: Pemodelan, Sistem Bantu, Kelayakan Pelayaran.

\begin{abstract}
This research can be carried out to carry out the shipping process to avoid accidents caused by accidents caused by the use of discharges and solutions by using the approach. This auxiliary system works for purposes. The auxiliary system in this research is in the form of optimization that can overcome the problem of ship's overnight in making the voyage. Test the eligibility of ships in a good and optimal shipping to avoid fatal accident is not possible without using a good data management system and realtime. With the auxiliary system, data processing and feasibility parameters become faster and produce decisions with a high degree of accuracy. Through this research, we are able to improve the quality of ship's eligibility in shipping well in strategic and operational aspects. The research was conducted by using survey method, model and system development. The expected result is a prototype and a vessel assistive aerial system for carrying out shipping that can be implemented to address and reduce the number of marine accidents in the voyage..
\end{abstract}

Keywords: Modeling, System Aid, Sailing Eligibility

\section{PENDAhuluan}

$\mathrm{S}$ arana transportasi laut yang memenuhi syarat pelayaran sangat diperlukan agar memudahkan angkutan barang ataupun orang bagi kawasan tersebut. Para stakeholders atau dalam hal ini pihak perusahaan yang menangani transportasi penyeberangan kapal ferry ini memiliki tanggungjawab penuh terhadap izin berlayar meliputi seluruh layanan yang dibutuhkan untuk menyambut kedatangan kapal ferry berikut muatannya, dan/atau mempersiapkan kapal-kapal ferry berikut muatannya untuk keberangkatan selanjutnya. Untuk itu dalam pengambilan keputusan kesiapan keberangkatan setiap kapal ferry yang ada harus benar-benar tepat demi keselamatan dalam pelayaran sesuai dengan jadwal kebarangkatan yang telah ditetapkan. Apabila hal ini tidak diputuskan dengan baik demi keselematan pengguna transportasi ini, maka mobilitas masyarakat juga mengalami gangguan.

Dengan semakin tingginya pertumbuhan ekonomi sebuah kota dikarenakan arus transportasi laut antar daerah/kota tersebut telah terhubung dengan baik. Angkutan laut di sulawesi tenggara kiranya masih mempunyai peran yang penting dan dominan dalam menunjang kelancaran angkutan barang serta penumpang antara satu pulau dengan pulau lainnya di Sulawesi Tenggara atau dengan pulau-pulau lainnya di Sulawesi Tenggara, namun tingkat kecelakaan transportasi laut di Sulawesi Tenggara terbilang tinggi.

Secara topografi, wilayah Sulawesi Tenggara banyak menggunakan transportasi laut. Menurut Search and Resque (SAR) Kendari, dalam empat tahun terakhir (2012-2015), jumlah kecelakaan transportasi laut di perairan Sulwesi Tenggara mencapai 132 kasus. Sebanyak 4.082 orang berhasil diselamatkan, 81 orang meninggal dunia dan 53 orang tidak ditemukan. Namun, dari berbagai lokasi kejadian, rute Kolaka-Bajoe dan Kolaka-Siwa yang 
terbanyak merenggut nyawa. Perairan Kolaka dan Teluk Bone dianggap paling ganas beberapa tahun terakhir. Sedikitnya ada tujuh musibah pelayaran terjadi di perairan tersebut. Kabupaten Kolaka pada tahun 2015 kasus KMP Marina Baru 2B yang menyebabkan 66 orang meninggal, 12 orang belum ditemukan dan 40 orang berhasil diselamatkan.

Untuk membantu mengatasi hal tersebut diatas maka diperlukan metode penyelesaian yang tepat dalam menyelesaikan permasalahan manajemen kelayakan operasional kapal laut dalam melakukan pelayaran dan mengoptimalkan pengambilan keputusannya telah digunakan secara luas. Penelitian membuktikan dengan menggunakan aplikasi yang mendukung pengambilan keputusan yang dapat mengontrol mesin kapal laut dapat dijadikan pedoman bagi syahbandar untuk mengeluarkan clarience atau surat izin [1].

Sistem Pendukung Keputusan (SPK) atau Computer Based Decision Support System (DSS) merupakan salah satu bagian dari sistem informasi yang berguna untuk meningkatkan efektifitas pengambilan keputusan (Turban, 2005). Oleh karena itu keputusan untuk menentukan kelayakan operasional kapal ferry perlu diperhitungkan dengan matang. Hal ini sering dilupakan, mereka hanya fokus pada beberapa hal teknis saja seperti kapasitas muatan dan bahan bakar, tidak mengkaji lebih dalam tentang dokumen fisik kapal dan sumber daya manusia.

Sistem program yang akan dibuat akan membantu mengatasi problem yang terjadi bagi syahbandar. Sistem yang akan dihasilkan akan lebih bersifat untuk membantu pengambil keputusan dan bukan menggantikannya. Diharapkan sistem ini juga dapat meningkatkan efektifitas dan efisiensi dari proses pengambilan keputusan itu sendiri sehingga mendapatkan hasil yang obyektif dari sejumlah kapal yang layak beroperasi atau berlayar.

\section{Metodologi.}

\section{A. Lokasi}

Penelitian ini dilaksanakan di PT ASDP Pelabuhan Ferry Kabupaten Kolaka Propinsi Sulawesi Tenggara yang berlangsung kurang lebih 2 (dua) bulan yakni bulan Mei sampai April 2017.

\section{B. Metode}

Teknik pengambilan data dilakukan, yaitu: data primer dan sekunder. Data primer yaitu data yang diperoleh melalui wawancara langsung dengan peternak. Data sekunder yaitu data yang diperoleh dari kantor dan instansi terkait dengan penelitian. Studi kepustakaan yaitu dengan melakukan penelusuran dari sejumlah literatur seperti jurnal, paper dan buku yang berkaitan dengan penelitian.

\section{Teknik Analisa Data}

Analisis data bertujuan untuk dapat menentukan parameter-parameter dalam masalah sebagai dasar kebutuhan sistem yang akan dibangun. Langkah-langkahnya meliputi :

a. Pemodelan : Pemodelan dimulai dari melakukan analisis dan evaluasi terhadap model realitas, yang kemudian diwujudkan dalam bentuk model MADM dengan metode Profile Matching. Model ini kemudian harus dapat merepresentasekan sistem atau masalah, dan dalam klasifikasi apa model ini akan dibangun.

b.Implementasi : Berdasarkan pemodelan yang telah dibangun, maka implementasi ke dalam piranti lunak dapat dilakukan berdasarkan hasil analisis kebutuhan sistem yang telah dimodelkan tersebut.

c. Pengujian : Pengujian atau evaluasi sistem untuk mengetahui tingkat keberhasilan sistem yang dibangun dan untuk mengetahui apakah fungsionalitas program telah tercapai. Pengujian dilakukan dengan kasus real (test case) mulai dari kebutuhan masukan, proses dan keluaran yang dibutuhkan sistem

\section{HASIL DAN PEMBAHASAN}

Profile Matching adalah sebuah mekanisme pengambilan keputusan dengan mengasumsikan bahwa terdapat tingkat variabel prediktor yang ideal yang harus dipenuhi oleh subyek yang diteliti, bukannya tingkat minimal yang harus dipenuhi atau dilewati [6].

Dalam proses Profile Matching secara garis besar merupakan proses membandingkan antara nilai data aktual dari suatu profile yang akan dinilai dengan nilai profil yang diharapkan, sehingga dapat diketahui perbedaan kompetensinya (disebut juga GAP), semakin kecil GAP yang dihasilkan maka bobot nilainya semakin besar.

Adapun parameter-parameter yang dapat dijadikan sebagai aspek penilaian dalam menilai Kelayakan Kapal dalam Pelayaran [8], dapat dilhat pada tabel I. 
TABEL I. PARAMETER PENILAIAN KAPAL

\begin{tabular}{|l|l|c|}
\hline \multicolumn{2}{|c|}{$\begin{array}{c}\text { Parameter Penilaian Kelayakan Kapal } \\
\text { Dalam Pelayaran }\end{array}$} & $\begin{array}{c}\text { Target } \\
\text { Nilai }\end{array}$ \\
\hline a. Aspek Admnistratif & C1. Manifest Muatan & 4 \\
& C2. Kewajiban Persetujuan & 5 \\
& C3. Sertifikat Kapal & 2 \\
& C4. Dokumen Pendukung & 3 \\
\hline b. Aspek Pemeriksaan Fisik Dalam Rangka & Port Clearance & \\
Penerbitan Surat Persetujuan Berlayar (Port & C1. Nautis, Teknis dan Radio & 5 \\
Clearance) & C2. Pemuatan dan Stabilitas & 4 \\
& C3. Pengawakan & 4 \\
& C4. Pemeriksaan Tambahan & 3 \\
\hline
\end{tabular}

Sedangkan bentuk penilaian berdasarkan skala oridinal, yaitu:

1. Sangat kurang

2. Kurang

3. Cukup

4. Baik

5. Sangat Baik

Hasil penelusuran di berbagai lokasi penelitian, maka diperoleh 6 (enam) armada kapal yang bisa dijadikan alternatif dalam penilaian berdasarkan parameter yang telah disiapkan (PT ASDP Kolaka).

\section{A. Pemodelan}

Berikut ini adalah parameter penilaian yang dituangkan dalam sebuah model penilaian, yaitu:

a. Nilai Aspek Admnistratif

Aspek Pemeriksaan Admnistratif Dalam Rangka Pemeriksaan Fisik Kapal sebelum dan sesudah keberangkatan dapat dilihat pada tabel II.

TABEL II. NILAI ASPEK ADMINISTRATIF

\begin{tabular}{|c|l|c|c|c|c|}
\hline No. & Nama Kapal & C1 & C2 & C3 & C4 \\
\hline 1 & KMP. Raja Laut & 2 & 3 & 3 & 4 \\
\hline 2 & KMP. Kota Muna & 2 & 2 & 3 & 4 \\
\hline 3 & KMP. Marina Baru & 3 & 2 & 2 & 3 \\
\hline 4 & KMP. Pelangi & 3 & 4 & 3 & 2 \\
\hline 5 & KMP. Darma Kartika & 4 & 3 & 4 & 2 \\
\hline 6 & KMP. Kota Bumi & 3 & 4 & 2 & 3 \\
\hline
\end{tabular}

b.Nilai Aspek Fisik

Aspek Pemeriksaan Fisik Dalam Rangka Penerbitan Surat Persetujuan Berlayar (Port Clearance) dapat dilihat pada tabel III.

TABEL III. NILAI ASPEK FISIK

\begin{tabular}{|c|l|c|c|c|c|}
\hline No. & Nama Kapal & C1 & C2 & C3 & C4 \\
\hline 1 & KMP. Raja Laut & 3 & 3 & 3 & 4 \\
\hline 2 & KMP. Kota Muna & 3 & 2 & 4 & 4 \\
\hline 3 & KMP. Marina Baru & 2 & 2 & 3 & 3 \\
\hline 4 & KMP. Pelangi & 3 & 4 & 2 & 2 \\
\hline 5 & KMP. Darma Kartika & 4 & 3 & 4 & 2 \\
\hline 6 & KMP. Kota Bumi & 3 & 4 & 2 & 3 \\
\hline
\end{tabular}

\section{c. Pemetaan GAP Kompetensi}

GAP adalah perbedaan/selisih value masing-masing aspek/attribut dengan value target. Formula GAP adalah seperti berikut

$G A P=V$ alueAttribut - Value Target

Tabel perhitungan GAP aspek administratif dengan nilai target $[4 ; 5 ; 2 ; 3]$ dapat dilihat pada table IV dan tabel perhitungan GAP aspek fisik dengan nilai target $[5 ; 4 ; 4 ; 3]$ pada table $\mathrm{V}$.

TABEL IV. GAP ASPEK ADMINISTRATIF

\begin{tabular}{|c|l|c|c|c|c|}
\hline No. & Nama Kapal & C1 & C2 & C3 & C4 \\
\hline 1 & KMP. Raja Laut & -2 & -2 & 1 & 1 \\
\hline 2 & KMP. Kota Muna & -2 & -3 & 1 & 1 \\
\hline 3 & KMP. Marina Baru & -1 & -3 & 0 & 0 \\
\hline 4 & KMP. Pelangi & -1 & -1 & 1 & -1 \\
\hline 5 & KMP. Darma Kartika 1 & 0 & -2 & 2 & -1 \\
\hline 6 & KMP. Kota Bumi & -1 & -1 & 0 & 0 \\
\hline
\end{tabular}


TABEL V. GAP ASPEK FISIK

\begin{tabular}{|c|l|c|c|c|c|}
\hline No. & Nama Kapal & C1 & C2 & C3 & C4 \\
\hline 1 & KMP. Raja Laut & -2 & -1 & -1 & 1 \\
\hline 2 & KMP. Kota Muna & -2 & -2 & 0 & 1 \\
\hline 3 & KMP. Marina Baru & -3 & -2 & -1 & 0 \\
\hline 4 & KMP. Pelangi & -2 & 0 & -2 & -1 \\
\hline 5 & KMP. Darma Kartika 1 & -1 & -1 & 0 & -1 \\
\hline 6 & KMP. Kota Bumi & -2 & 0 & -2 & 0 \\
\hline
\end{tabular}

\section{d.Pembobotan}

Setelah diperoleh GAP pada masing-masing kapal, setiap profil kapal diberi bobot nilai sesuai ketentuan pada Tabel Bobot Nilai GAP. Tabel Bobot Nilai GAP dapat dilihat pada table VI.

TABEL VI. BOBOT NILAI GAP

\begin{tabular}{|c|c|l|}
\hline Selisih & Bobot Nilai & \multicolumn{1}{|c|}{ Keterangan } \\
\hline 0 & 5.0 & Tidak ada selisih \\
1 & 4.5 & Kompetensi kapal kelebihan 1 tingkat \\
-1 & 4.0 & Kompetensi kapal kekurangan 1 tingkat \\
2 & 3.5 & Kompetensi kapal kelebihan 2 tingkat \\
-2 & 3.0 & Kompetensi kapal kekurangan 2 tingkat \\
3 & 2.5 & Kompetensi kapal kelebihan 3 tingkat \\
-3 & 2.0 & Kompetensi kapal kekurangan 3 tingkat \\
4 & 1.5 & Kompetensi kapal kelebihan 4 tingkat \\
-4 & 1.0 & Kompetensi kapal kekurangan 4 tingkat \\
\hline
\end{tabular}

Konversi nilai hasil pemetaan GAP Kompetensi ke nilai bobot GAP. Nilai Bobot GAP Aspek Administratif dapat dilihat pada table VII dan Bobot GAP Aspek Fisik table VIII.

TABEL VII. BOBOT GAP ASPEK ADMINISTRATIF

\begin{tabular}{|c|l|c|c|c|c|}
\hline No. & Nama Kapal & $\mathrm{C} 1$ & $\mathrm{C} 2$ & $\mathrm{C} 3$ & $\mathrm{C} 4$ \\
\hline 1 & KMP. Raja Laut & 3 & 3 & 4.5 & 4.5 \\
\hline 2 & KMP. Kota Muna & 3 & 2 & 4.5 & 4.5 \\
\hline 3 & KMP. Marina Baru & 4 & 2 & 5 & 5 \\
\hline 4 & KMP. Pelangi & 4 & 4 & 4.5 & 4 \\
\hline 5 & KMP. Darma Kartika & 5 & 3 & 3.5 & 4 \\
\hline 6 & KMP. Kota Bumi & 4 & 4 & 5 & 5 \\
\hline
\end{tabular}

TABEL VIII. BOBOT GAP ASPEK FISIK

\begin{tabular}{|c|l|c|c|c|c|}
\hline No. & Nama Kapal & C1 & C2 & C3 & C4 \\
\hline 1 & KMP. Raja Laut & 3 & 4 & 4 & 4.5 \\
\hline 2 & KMP. Kota Muna & 3 & 3 & 5 & 4.5 \\
\hline 3 & KMP. Marina Baru & 2 & 3 & 4 & 5 \\
\hline 4 & KMP. Pelangi & 3 & 5 & 3 & 4 \\
\hline 5 & KMP. Darma Kartika & 4 & 4 & 5 & 4 \\
\hline 6 & KMP. Kota Bumi & 3 & 5 & 3 & 5 \\
\hline
\end{tabular}

e. Perhitungan Core dan Secondary Factor

Setelah menentukan bobot nilai GAP untuk kedua aspek, yaitu: aspek administrative dan aspek fisik kemudian dengan cara yang sama, setiap aspek dikelompokkan menjadi 2 kelompok yaitu: "Core Factor" dan "Secondary Factor".

Core factor merupakan aspek (kompetensi) yang paling menonjol/paling layak beroperasi yang diperkirakan dapat menghasilkan operasional optimal. Formula yang digunakan untuk mencari nilai Core Factor adalah

$\mathrm{NS}=\frac{\sum \mathbf{N C}}{\sum \mathbf{I C}}$

Keterangan :

$$
\begin{aligned}
& \mathrm{NCF}=\text { Nilai rata-rata core factor } \\
& \mathrm{NC}=\text { Jumlah total nilai core factor } \\
& \mathrm{IC}=\text { Jumlah item core factor }
\end{aligned}
$$

Secondary factor adalah item-item selain aspek yang ada pada core factor, maka untuk menghitung secondary factor digunakan rumus :

$\mathrm{NSF}=\frac{\sum \mathrm{NS}}{\sum \mathrm{IS}}$ 
Keterangan :

$$
\begin{aligned}
& \text { NSF = Nilai rata-rata secondary factor } \\
& \text { NS = Jumlah total nilai secondary factor } \\
& \text { IS = Jumlah item secondary factor }
\end{aligned}
$$

Aspek Administratif perhitungan core factor ( $\mathrm{C} 1$ dan $\mathrm{C} 2)$ dan secondary factor (C3 dam $\mathrm{C} 4)$.

TABEL IX. CORE DAN SECONDARY FACTOR ASPEK ADMINISTRTIF
\begin{tabular}{|c|l|c|c|c|c|c|c|}
\hline No. & Nama Kapal & $\mathrm{C} 1$ & $\mathrm{C} 2$ & $\mathrm{C} 3$ & $\mathrm{C} 4$ & NCF & NSF \\
\hline 1 & KMP. Raja Laut & 3 & 3 & 4.5 & 4.5 & 3 & 4.5 \\
\hline 2 & KMP. Kota Muna & 3 & 2 & 4.5 & 4.5 & 2.5 & 4.5 \\
\hline 3 & KMP. Marina Baru & 4 & 2 & 5 & 5 & 3 & 5 \\
\hline 4 & KMP. Pelangi & 4 & 4 & 4.5 & 4 & 4 & 4.25 \\
\hline 5 & KMP. Darma Kartika 1 & 5 & 3 & 3.5 & 4 & 4 & 3.75 \\
\hline 6 & KMP. Kota Bumi & 4 & 4 & 5 & 5 & 4 & 5 \\
\hline
\end{tabular}

Aspek Fisik perhitungan core factor (C1 dan $\mathrm{C} 2)$ dan secondary factor (C3 dam $\mathrm{C} 4)$.

TABEL X. CORE DAN SECONDARY FACTOR ASPEK FISIK

\begin{tabular}{|c|l|c|c|c|c|c|c|}
\hline No. & Nama Kapal & C1 & C2 & C3 & C4 & NCF & NSF \\
\hline 1 & KMP. Raja Laut & 3 & 4 & 4 & 4.5 & 3.5 & 4.25 \\
\hline 2 & KMP. Kota Muna & 3 & 3 & 5 & 4.5 & 3 & 4.75 \\
\hline 3 & KMP. Marina Baru & 2 & 3 & 4 & 5 & 2.5 & 4.5 \\
\hline 4 & KMP. Pelangi & 3 & 5 & 3 & 4 & 4 & 3.5 \\
\hline 5 & KMP. Darma Kartika 1 & 4 & 4 & 5 & 4 & 4 & 4.5 \\
\hline 6 & KMP. Kota Bumi & 3 & 5 & 3 & 5 & 4 & 4 \\
\hline
\end{tabular}

f. Perhitungan Nilai Total

Dari perhitungan setiap aspek yang diatas, berikutnya dihitung nilai total berdasarkan persentase dari core factor dan secondary factor yang diperkirakan berpengaruh terhadap kinerja tiap-tiap kapal dengan rumus:

$\mathrm{N}=(\mathrm{NCFk} \%)+(\mathrm{NSFk} \%)$

dimana $\mathrm{k}=$ nilai persen yang diinputkan.

Perhitungan aspek administratif 60\% dan dan aspek fisik 40\% seperti pada tabel XI dan XII.

Tabel XI. Nilai Total Aspek Administratif

\begin{tabular}{|c|l|c|c|c|}
\hline No. & Nama Kapal & NCF & NSF & N1 \\
\hline 1 & KMP. Raja Laut & 1.8 & 1.8 & 3.6 \\
\hline 2 & KMP. Kota Muna & 1.5 & 1.8 & 3.3 \\
\hline 3 & KMP. Marina Baru & 1.8 & 2 & 3.8 \\
\hline 4 & KMP. Pelangi & 2.4 & 1.7 & 4.1 \\
\hline 5 & KMP. Darma Kartika 1 & 2.4 & 1.5 & 3.9 \\
\hline 6 & KMP. Kota Bumi & 2.4 & 2 & 4.4 \\
\hline
\end{tabular}

Tabel XII. Nilai Total Aspek Administratif

\begin{tabular}{|c|l|c|c|c|}
\hline No. & Nama Kapal & NCF & NSF & N2 \\
\hline 1 & KMP. Raja Laut & 2.1 & 1.7 & 3.8 \\
\hline 2 & KMP. Kota Muna & 1.8 & 1.9 & 3.7 \\
\hline 3 & KMP. Marina Baru & 1.5 & 1.8 & 3.3 \\
\hline 4 & KMP. Pelangi & 2.4 & 1.4 & 3.8 \\
\hline 5 & KMP. Darma Kartika 1 & 2.4 & 1.8 & 4.2 \\
\hline 6 & KMP. Kota Bumi & 2.4 & 1.6 & 4 \\
\hline
\end{tabular}

g.Penentuan Perankingan

Hasil akhir dari proses ini adalah rangking dari alternative (kapal) yang diuji kelayakan operasional dalam pelayaran, maka dapat dilihat kapal yang memiliki performansi terbaik dengan nilai tertinggi dari hasil perhitungan yang ditujukan pada rumus dibawah ini :

$$
D=\sum_{i=1}^{n} N i j x \%
$$

Keterangan :

$$
\begin{aligned}
& \mathrm{D}=\text { Nilai Ranking } \\
& \mathrm{i}=1,2, \ldots . ., \mathrm{n} \\
& \mathrm{x} \%=\text { nilai persen yang diinputkan }
\end{aligned}
$$


TABEL XIII. HASIL PERANKINGAN

\begin{tabular}{|c|l|c|c|c|}
\hline No. & Nama Kapal & N1 & N2 & N \\
\hline 1 & KMP. Darma Kartika & 3.9 & 4.2 & 42.0 \\
\hline 2 & KMP. Kota Bumi & 4.4 & 4 & 41.6 \\
\hline 3 & KMP. Pelangi & 4.1 & 3.8 & 39.2 \\
\hline 4 & KMP. Raja Laut & 3.6 & 3.8 & 37.2 \\
\hline 5 & KMP. Kota Muna & 3.3 & 3.7 & 36.0 \\
\hline 6 & KMP. Marina Baru & 3.8 & 3.3 & 35.0 \\
\hline \multicolumn{4}{|c|}{ Nilai Tertinggi } & $\mathbf{4 2 . 0}$ \\
\hline
\end{tabular}

Setelah setiap kapal mendapatkan hasil akhir seperti pada tabel XIII diatas, maka bisa ditentukan peringkat atau ranking dari kandidat berdasarkan pada semakin besarnya nilai hasil akhir, maka kapal tersebut memiliki performansi terbaik dalam melakukan pelayaran baik secara administratif maupun secara fisik sedagkan nilai rendah dapat dipertimbangkan dal am pelayaran dengan beberapa opsi lain, diantaranya Perawatan ditempat atau Doking. Pada hasil penilaian dari kasus di atas yang memiliki nilai terbesar adalah KMP. Darma Kartika 1 dengan nilai 42.0.

\section{B. Implementasi}

Berikut ini adalah parameter penilaian yang diimplementasikan dalam sebuah piranti lunak, yaitu:

a. Form Menu Utama

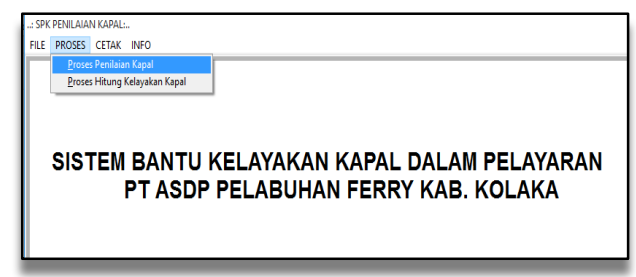

Gambar I. Menu Utama

b.Form Data Identitas Kapal

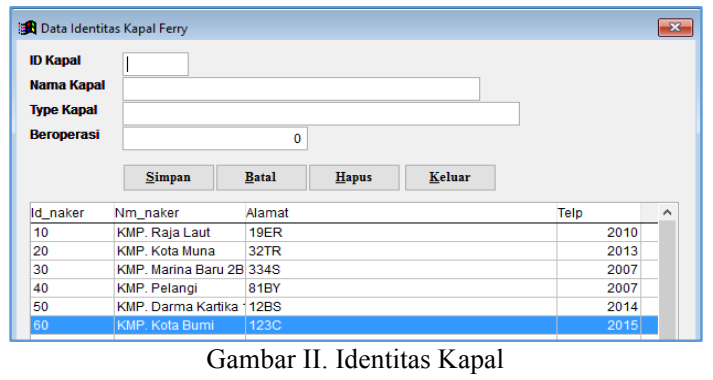

c. Form Penilaian Kapal

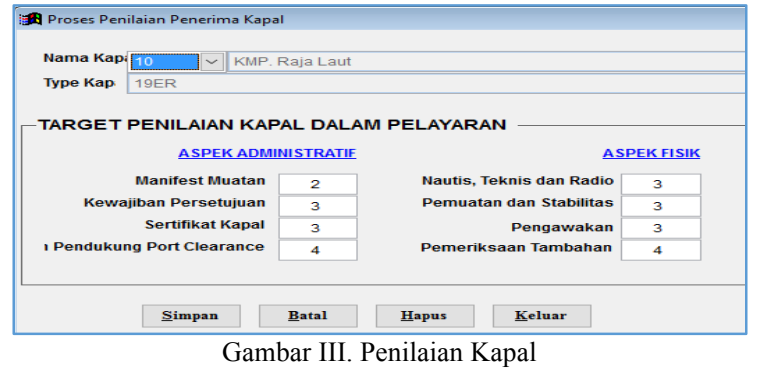

d.Form Proses Pehitungan

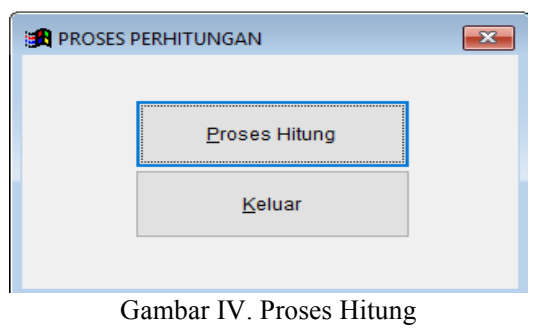


e. Form Cetak Data

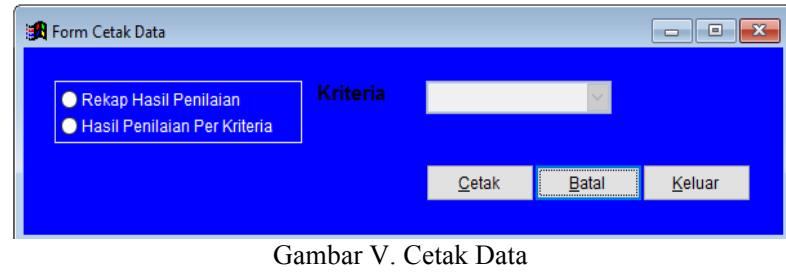

f. Output Sistem

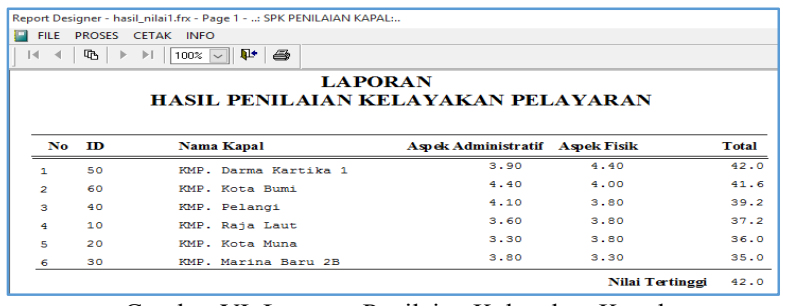

Gambar VI. Laporan Penilaian Kelayakan Kapal

\section{Pengujian Sistem}

Pengujian sistem dilakukan dengan menelusuri aturan pemodelan metode Profile Matching dan mengevaluasi hasil yang diberikan sistem sesuai dengan harapan. Jika hasil yang diperoleh tidak sesuai dengan yang diharapkan berdasarkan parameter penilaian yang ada, maka perlu dilakukan perbaikan. Hasil pengujian yang dilakukan oleh peneliti menunjukkan perhitungan yang diberikan oleh Aplikasi yang telah dirancang menghasilkan nilai yang serupa dengan perhitungan secara manual.

\section{KESIMPULAN}

Dengan menerapkan sistem bantu kelayakan pelayaran dengan metode profile matching menghasilkan beberapa kesimpulan sebagai berikut:

a) Metode yang digunakan sesuai dengan yang diharapkan, yaitu dapat membantu pihak Syahbandar dan PT ASDP Kab. Kolaka dalam menilai kapal yang benar-benar layak melakukan pelayaran dari beberapa alternatif Kapal yang ada.

b) Data parameter penilaian, dan data alternatif (Kapal), dan penilaian pada sistem bantu ini bersifat dinamis yang dapat disesuakan sesuai dengan kebutuhan pengguna sistem atau instansi terkait.

\section{REFERENSI}

[1] Ario Hananto, 2015. Aplikasi Sistem Informasi dan Sistem Pendukung Keputusan Kamar Mesin Kapal Penumpang, Jurnal Ilmiah Universitas Surabaya, Vol. 4, No. 1. Hal. 1-9

[2] Benny, 2010. Safety Equipment Terhadap Keselamatan Berlayar, Jurnal Aplikasi Pelayaran dan Kepelabuhanan, Vol. 1, No. 1, September 2010, Hal. 69-78

[3] BPS Prop. Sultra, 2014. Statistik Transportasi Provinsi Sulawesi Tenggara.

[4] Denny Faturachman, 2015. Analisis Keselamatan Transportasi Penyeberangan Laut Dan Antisipasi Terhadap Kecelakaan Kapal, Jurnal Teknik Mesin Untirta, Vol. I, No. 1, April 2015, Hal. 14-21

[5] Herawati. Analisis Kelayakan Kebutuhan Pelabuhan Dan Keselamatan Pelayaran. Publishing Konstruksi.

[6] Kusrini. 2007. Konsep dan Aplikasi Sistem Pendukung Keputusan. Andi. Yogyakarta.

[7] Muh. Arif \& Febry Y., 2015. Implementasi Kebijakan Keselamatan Pelayaran, Jurnal Administrasi Pembangunan, Vol. II, No. 3, Juli 2014, Hal. 259-264

[8] Permenhub No KM 01, 2010. Tentang Tata cara PenerbitanSurat Izin Berlayar (Port Clearance).

[9] Permenhub No KM 21, 2007. Tentang Sistem Dan Prosedur Pelayanan Kapal, Barang Dan Penumpang Pada Pelabuhan Laut Yang Diselenggarakan Oleh Unit Pelaksanan Teknis (UPT) Kantor Pelabuhan.

[10] Qammaddin, 2012. Model Sistem Pengambilan Keputusan Ground Handling. Trussmedia Yogyakarta.

[11] Tenda BB, 2015. Tinjauan Yuridis Mengenai Peran Syahbandar Dalam Kegiatan Pelayaran Angkutan Laut Di Indonesia, Jurnal Lex et Societatis, Vol. III, No. 3, April 2015, Hal. 25-36

[12] Undang-Undang Republik Indonesia Nomor 17. 2008. Tentang Pelayaran.

[13] Simartama, Janner. 2007. Perancangan Basis Data. Andi Yogyakarta.

[14] Syaukani. M. 2006. "Menguasai Microsoft FoxPro 9. PT. Elex Media Komputindo. Jakarta. 